\title{
Spontaneous haemoperitoneum from rupture of a primary hepatic adenoma in an adult man
}

\author{
P D MCINERNEY, M G VAN DESSEL, AND D A BERSTOCK \\ From the Department of Surgery, Clatterbridge Hospital, Bebington, Wirral, Cheshire
}

SUmmary Hepatic cell adenomata have been described as the rarest of benign liver tumours.' Their incidence has increased with the advent of the oral contraceptive pill and they have been reported to rupture spontaneously in women. In men such a phenomenon appears to be an extreme rarity $^{2}$ and, to our knowledge, spontaneous rupture of an uncomplicated primary hepatic adenoma, in an adult man, is previously unrecorded.

\section{Case report}

A 72 year old man presented with a three day history of nausea, right sided abdominal pain and right shoulder tip pain of sudden onset. On examination he was unwell, with a pyrexia of $38^{\circ} \mathrm{C}$, pulse $70 / \mathrm{min}$ and blood pressure $120 / 70 \mathrm{~mm} \mathrm{Hg}$. He had signs of a right basal pleural effusion and generalised peritonism. Initial investigations revealed a haemoglobin level of $10 \cdot 2 \mathrm{~g} / \mathrm{dl}$, white blood cell count of $19 \cdot 4 \times 10^{9} / \mathrm{l}$ and a serum amylase of $260 \mathrm{IU} / \mathrm{l}$. Chest radiograph confirmed a basal pleural effusion and abdominal radiographs were unremarkable.

In view of the unexplained peritonism a laparotomy was carried out. This revealed haemoperitoneum, the source of which was a $14 \mathrm{~cm}$ diameter cavity, opening onto the lateral subdiaphragmatic aspect of the right lobe of the liver. The cavity was evacuated of clots, revealing multiple bleeding points, its wall was biopsied and the cavity was then packed. A transfusion of 7 units of blood was required in the ensuing 24 hours. Two days later a second laparotomy was carried out, the packs were removed, and a vacuum drain was inserted into the cavity.

Subsequent investigations revealed markedly raised liver transaminases consistent with hepatocellular damage. Histology of the biopsy showed a hepatic adenoma containing an area of necrosis (Fig. 1). Histology of the left lobe of the liver, obtained by

Address for correspondence: D A Berstock, FRCS, Consultant Surgeon. Clatterbridge Hospital, Bebington, Wirral, Cheshire.

Received for publication 5 February 1987.

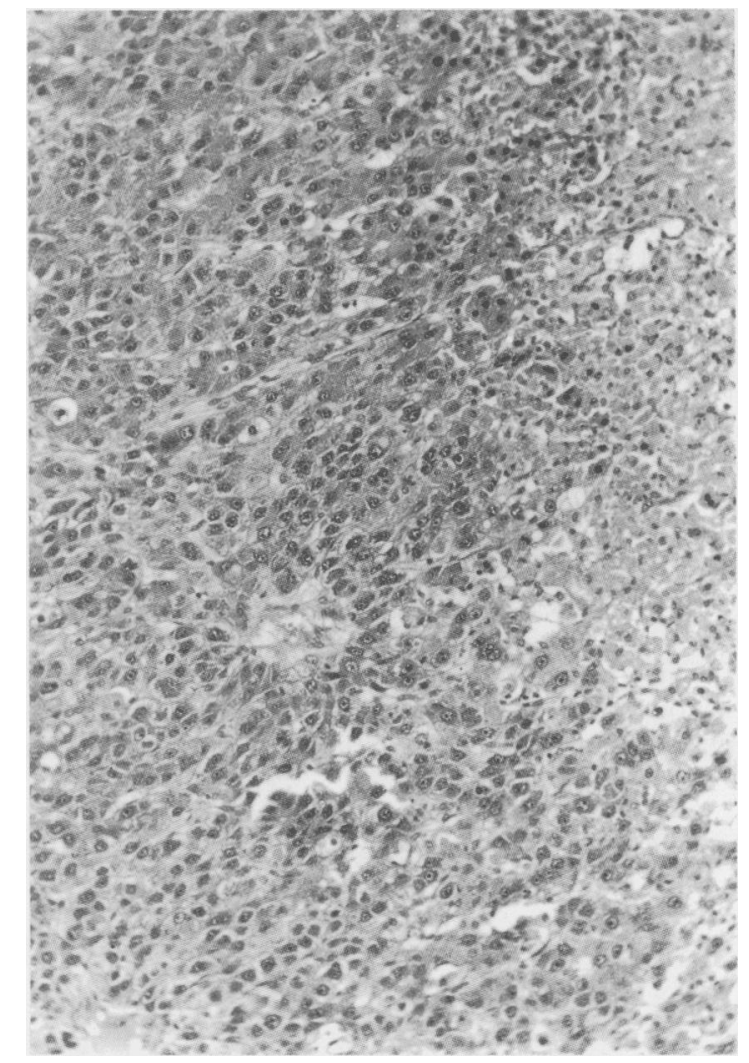

Fig. 1 Photomicrograph $(10 \times 20)$ showing normal-looking hepatocytes separated by sinusoidal spaces, some of which are dilated. No bile ducts are seen. An area of necrosis is included. 


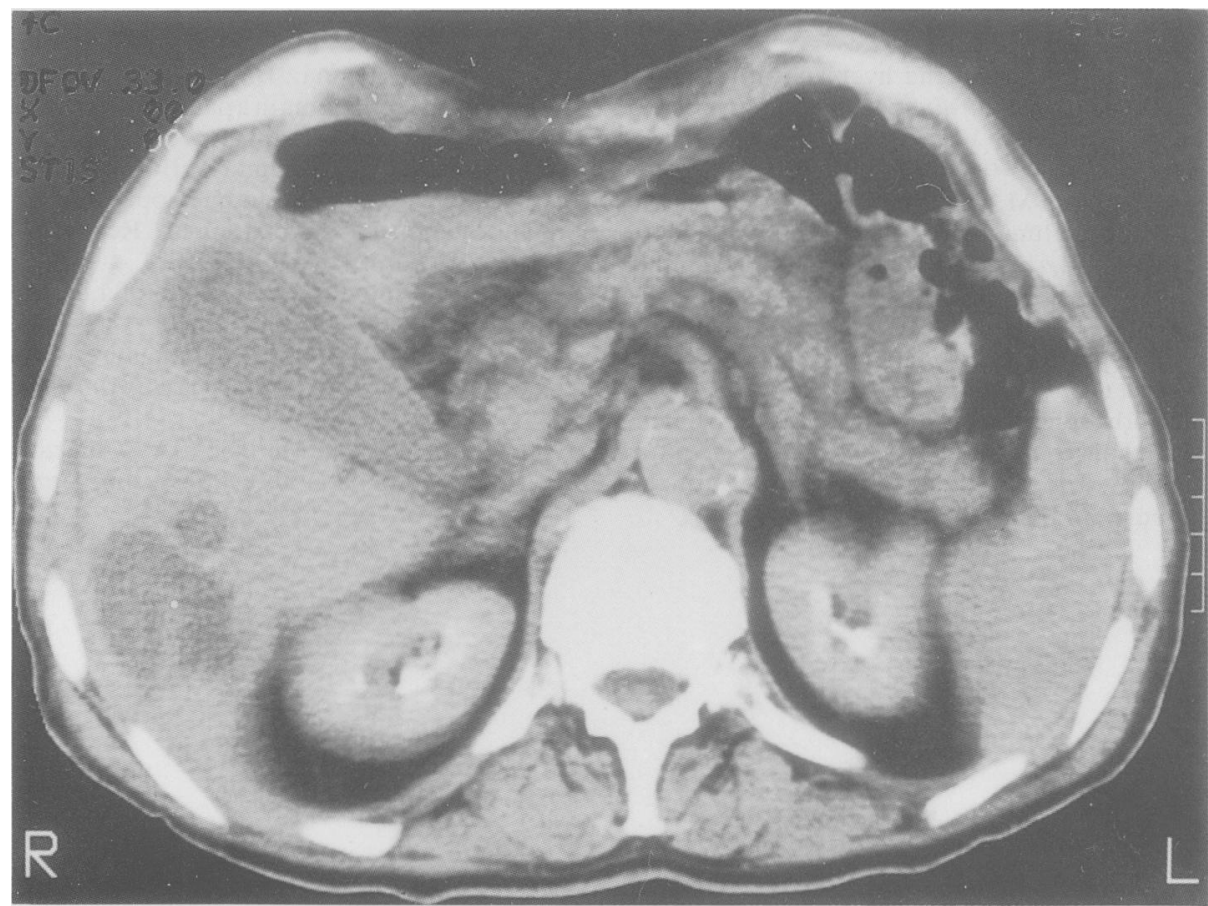

Fig. 2 Abdominal CT scan showing one slice of a contrast enhanced series. There is an irregular lesion in the lateral aspect of the right lobe of liver. The appearances are consistent with that of a cavitating adenoma.

needle biopsy at laparotomy, was unremarkable. A computed tomography liver scan demonstrated the cavity, within an extensive lesion involving much of the right lobe of the liver (Fig. 2), consistent with an adenoma. Investigations for an endogenous source of steroid production, including 24 hour urinary cortisol, plasma testosterone, sex hormone binding globulin and radiography of the pituitary fossa were within normal limits, apart from a raised serum cortisol concentration consistent with recent surgery. No steroids or oestrogens had been given. The patient made an uneventful recovery and no further surgery for the residual adenoma is envisaged in view of the patient's age.

\section{Discussion}

Benign liver cell adenoma is characterised by cords of well differentiated hepatocytes, uninterrupted by portal tracts or normal lobular formations.' The aetiology is uncertain, but appears to be associated with increased levels of endogenous or exogenous steroids. Pregnancy and the oral contraceptive pill ${ }^{45}$ have been incriminated. In men, the endogenous production of anabolising androgens should be excluded." Whether the steroids predispose to the condition, or whether they merely exacerbate its progress and precipitate clinical presentation, remains to be elucidated.

Spontaneous rupture, with consequent haemoperitoneum, is the mode of presentation in women in approximately one third of previously reported cases. ${ }^{3+7}$

Operative intervention is almost invariably necessary. Procedures undertaken, usually in young women, include limited local resections, sublobar resection with ligation of the hepatic artery, and lobectomy, ${ }^{+\times y}$ as the lesion tends to be restricted to one lobe. Results vary but mortality figures of up to $50 \%$ are quoted. In this particular case the management was influenced by the patient's age and unsuitability for a major hepatic resection, but, in the short term at least this does not appear to have compromised his survival. Subsequent endocrine investigations failed to show an intrinsic cause for the adenoma which must be regarded as primary.

Insufficient is known about the propensity of these unresected tumours to rebleed, to suggest whether or not further operative treatment is indicated. 


\section{References}

1 Edmondson HA. Tumors of the liver and intrahepatic bile ducts. Armed Forces Institute of pathology atlas of tumor pathology, Section VII Fascicle 25. Washington DC: National Research Council, 1958: 18-9.

2 Descottes B, Kalfon M, Rousseau D, Grousseau D, Catanzo G. Benign tumours of the liver. Haemoperitoneum caused by rupture of a hepatic adenoma. Chirurgie 1981; 107: 176-7.

3 Kent DR, Nissen ED, Nissen SE, Ziehm DJ. Effect of Pregnancy on liver tumour associated with oral contraceptives. Obstet Gynecol 1978; 51: 148-51.

4 Mays ET, Christopherson WM, Mahr MM, Williams HC. Hepatic changes in young women ingesting contraceptive steroids. Hepatic haemorrhage and primary hepatic tumours. JAMA 1976; 235: 730-2.
5 Antoniades Kristina, Brooks CE. Haemoperitoneum from liver cell adenoma in a patient on oral contraceptives. Surgery 1975; 77: 137-9.

6 Coca A, Munnie P, Anguita A, Borrias A, Camp J, Millia $\mathrm{J}$. Acute abdomen due to haemoperitoneum as the first manifestation of a liver tumour. Report of four cases. Med Clin (Barc) 1979; 10: 97-102.

7 Scorer CG. Spontaneous rupture of a hepatic adenoma. BrJ Surg 1969; 56: 633-5.

8 Albritton DR, Tomkins RK, Longmire WP. Hepatic cell adenoma. A report of four cases. Ann Surg 1974; 180: 14-9.

9 Longmire WP Jr, Marable SA. Clinical experiences with major hepatic resections. Ann Surg 1961; 154: 460 . 